\title{
Presence of acute phase response in coal workers' pneumoconiosis
}

\author{
G Fernandez Rego, G Ocio Achaerandio, V González Cuervo, C Rodríquez Menéndez, \\ C Martínez González, C Alvarez Alvarez
}

\begin{abstract}
To evaluate the role of personal factors in pneumoconiosis, several acute phase proteins were studied in 62 coal miners without acute illnesses and classified as having no pneumoconiosis $(n=19)$, simple pneumoconiosis $(n=$ 23), or complicated pneumoconiosis with progressive massive fibrosis $(n=20)$. Groups were similar for age, years of work at high risk jobs, chronic bronchitis, and forced expiratory volume in one second $\left(\mathrm{FEV}_{1}\right)$. C-reactive protein concentration was significantly higher in the simple and complicated pneumoconiosis groups in comparison with the no pneumoconiosis group. The $\mathrm{C}$-reactive protein concentration was above the upper normal value in 12 $(27.9 \%)$ out of 43 cases with simple and complicated pneumoconiosis. On the other hand only one case of no pneumoconiosis was above the upper normal range $(5 \cdot 3 \%)$, a significant difference taking into account a stratified analysis for chronic bronchitis. Fibrinogen concentration was significantly increased in the simple pneumoconiosis group compared with the no pneumoconiosis group. The value of fibrinogen was above the upper normal limit in 17 out of the 43 cases with pneumoconiosis $(39.5 \%)$ by contrast with two cases in the no pneumoconiosis group (10.5\%). No significant differences in $\alpha_{1}$-antitrypsin and ceruloplasmin concentrations were found between groups. In conclusion, an alteration in some acute phase proteins related to pneumoconiosis was found in miners. This could be used as a marker of disease activity and personal response against the pathogenic agent.
\end{abstract}

Instituto Nacional de Silicosis, Pulmonary Medicine, Laboratory, and Preventive Medicine Services, Oviedo, Spain

G F Rego, G O Achaerandio, V G Cuervo, C R Menéndez, C M González, C A Alvarez
It is generally agreed that quantitative exposure to coal dust is the most important factor in the development of pneumoconiosis. ${ }^{12}$ The greater the exposure to coal dust, the greater the probability of contracting the disease. It should, therefore, be possible to predict the number of cases of pneumoconiosis in a group of exposed workers to within a certain degree of accuracy.

For individual cases, however, owing to several personal factors, precise prediction is not yet possible. Some of these personal factors have been discussed in previous reports. Rasche et al found an increase in C-reactive protein (C-RP) in a group of coal miners considered as predisposed to pneumoconiosis. ${ }^{3}$ Nevertheless, in an earlier report, they had concluded that the increase in C-RP in miners was due to the presence of chronic bronchitis and not to pneumoconiosis. ${ }^{4}$ An increase in $\alpha_{1}$-antitrypsin $\left(\alpha_{1}-\right.$ AT) was found in miners with progressive massive fibrosis compared with controls by Hahon et al. ${ }^{5}$ Others, however, report no differences. ${ }^{6}$

Increases in bronchoalveolar lavage (BAL) cellularity and gallium- 67 uptake have been found in pneumoconiosis. ${ }^{78}$ An active process, similar in some aspects to an inflammation, might be the cause. If this is the case, an alteration in acute phase reaction might be expected. To determine if this were so, C-RP, fibrinogen, ceruloplasmin, and $\alpha_{1}$-AT were measured in coal miners exposed to similar occupational risk and suffering different types of pneumoconiosis.

Materials and methods

This study included 62 consecutive coal miners, (minimum age 50) sent to the clinic for periodic check ups between January and June 1988. They had no acute illnesses, and were not taking steroids or other anti-inflammatory drugs.

Subjects were interviewed by trained personnel. Case histories were completed and details about working conditions were obtained. To evaluate exposure risk, the factor considered was number of years of work in high risk jobs (face workers and drillers). The definition of ex-smoker was met if 
Table 1 Groups according to pneumoconiosis

\begin{tabular}{lccc}
\hline & No pneumoconiosis & Simple pneumoconiosis & Complicated pneumoconiosis \\
\hline No of cases & 19 & 23 & 20 \\
Mean age, (y (range)) & $62 \cdot 9(51-74)$ & $61 \cdot 5(51-75)$ & $62 \cdot 2(52-72)$ \\
Mean risk, (y (range)) & $17 \cdot 3(2-39)$ & $17 \cdot 4(2-34)$ & $18 \cdot 4(2-35)$ \\
Smokers & 14 & 15 & 14 \\
Ex-smokers & 10 & 8 & 12 \\
Chronic bronchitis & 8 & 2388 & $(581)$ \\
FEV (ml (SD)) & $2182(634)$ & 10 & 1801 \\
\hline
\end{tabular}

Table 2 Acute phase proteins according to pneumoconiosis

\begin{tabular}{|c|c|c|c|}
\hline Protein & No pneumoconiosis & Simple pneumoconiosis & Complicated pneumoconiosis \\
\hline $\begin{array}{l}\text { C-Reactive protein } \\
\text { Fibrinogen } \\
\text { Ceruloplasmin } \\
x_{1} \text {-Antitrypsin }\end{array}$ & $\begin{aligned} 0.23 & (0.34) \dagger \\
314.5 & (82 \cdot 3) \\
84.8 & (113 \cdot 4) \\
191.2 & (33)\end{aligned}$ & $\begin{aligned} 0.57 & (0.53)^{\star} \\
375 & (101.7)^{\star} \\
65.8 & (65.6) \\
193.7 & (35.3)\end{aligned}$ & $\begin{aligned} 1.6 & (3.5)^{\star} \\
371 & (123.5) \\
52.1 & (9.5) \\
213.7 & (93.9)\end{aligned}$ \\
\hline
\end{tabular}

${ }^{\star} \mathrm{p}<0.05 v$ no pneumoconiosis.

Mean $\mathrm{mg}$ protein/dl (SD).

smoking had stopped three months before the test. Chronic bronchitis was defined in the standard way. ${ }^{9}$ Chest radiographs were obtained and were read by three trained experts using the 1980 International Labour Office classification. ${ }^{10}$ Three groups were established-namely, no pneumoconiosis (profusion less than 1/1), simple pneumoconiosis, and complicated pneumoconiosis with progressive massive fibrosis. The simple and complicated pneumoconiosis groups form the pneumoconiosis group. Spirometric studies were performed using a Vitalograph spirometer. At least three trials were completed and the results were selected using standard criteria. ${ }^{11}$ Table 1 summarises the group characteristics. Blood samples were analysed by the following methods: C-reactive protein by an immunoturbidimetric test using goat antibodies (Boehringer, Mannheim); fibrinogen by the Clauss method, ${ }^{12}$ ceruloplasmin by radial immunodiffusion (Mancini, Behring Institute); and $\alpha_{1}$-AT by radial immunodiffusion (Mancini, Bio-Merieux).

Differences between means of the groups were compared by two tailed $t$ test. For C-RP the MannWhitney $U$ test was employed. A stratified analysis for chronic bronchitis (Mantel-Haenszel test) was applied to compare the number of C-RP and fibrinogen values above the upper normal limit in the pneumoconiosis and no pneumoconiosis groups. Proportions of abnormally high values in these two groups were compared with an appropriate test for unpaired data.

\section{Results}

Table 2 summarises the results. The concentration of C-RP was significantly increased in the simple and complicated pneumoconiosis groups compared with the no pneumoconiosis group $(\mathrm{p}<0.02)$. The value of C-RP was above the upper normal value in 12 out of 43 cases with pneumoconiosis $(27.9 \%)$. On the other hand, only one case in the no pneumoconiosis group was above the upper normal value $(5 \cdot 3 \%)$, a significant difference taking into account the stratified analysis for chronic bronchitis $(x=1.99$; $\mathrm{p}<0.05)$.

Fibrinogen concentration was significantly greater in the simple pneumoconiosis group in comparison with the no pneumoconiosis group $(t=2 \cdot 08$; $\mathrm{p}<0.05)$. The value of fibrinogen was above the upper normal range in 17 cases with pneumoconiosis $(39.5 \%)$ by contrast with two cases in the no pneumoconiosis group $(10.5 \%)(x=2.29 ; p<0.05)$.

The number of cases with abnormally high values for ceruloplasmin and $\alpha_{1}$-AT were nine $(20 \%)$ and four $(10 \%)$ in the pneumoconiosis group and $4(21 \%)$

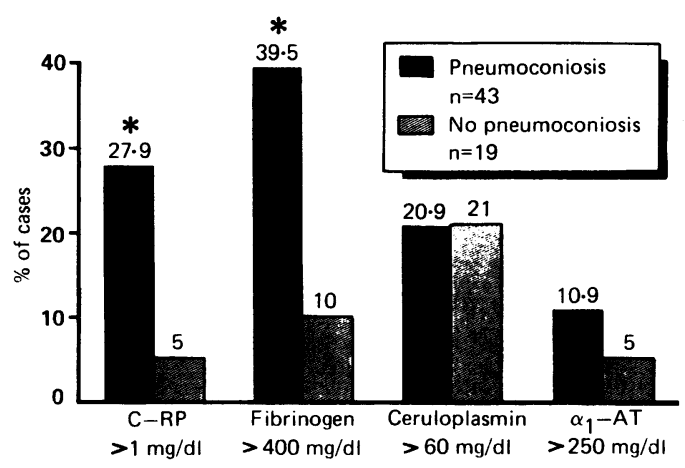

Per cent of cases with values of acute phase proteins above upper normal range in coal miners according to presence or absence of pneumoconiosis. $C-R P=C$-reactive protein; $\alpha_{1}-A T=\alpha_{1}$-antitrypsin. ${ }^{\star} p<0.05$. 
and one (5\%) in the no pneumoconiosis group. These differences were not significant.

The figure shows the percentages of cases with values above the upper normal limit in the pneumoconiosis and no pneumoconiosis groups.

\section{Discussion}

In the present study, we found a non-uniform alteration in acute phase proteins in the miners studied. Fibrinogen and C-RP concentrations were increased in relation to the presence of pneumoconiosis. Concentrations of ceruloplasmin, an important serum antioxidant, were increased in some cases, but had no relation to pneumoconiosis; $\alpha_{1}$-AT values were not significantly altered.

Other studies have examined several of these proteins with conflicting results. Hahon $e t$ al ${ }^{5}$ found an increase in $\alpha_{1}$-AT concentration in miners with progressive massive fibrosis compared with controls. These differences were not found, however, in other studies. ${ }^{6}$ Rasche et al found an increase in C-RP concentration in a group of coal miners considered as predisposed to pneumoconiosis ${ }^{3}$ by contrast with an earlier report in which they had concluded that the increase in C-RP in miners was due to the presence of chronic bronchitis and not to pneumoconiosis. ${ }^{4}$ This apparent contradiction with our results may be because our cases were studied when they were in a stable situation with no signs of acute illness.

The significance of C-RP measurement for monitoring the acute phase response has recently been emphasised. ${ }^{13}$ This response is basically started by interleukin- $1,{ }^{14}$ a potent mediator that is considered to be a pathogenic factor in silicosis. ${ }^{15}$

Bronchoalveolar lavage and gallium uptake studies suggest an inflammatory process related to pneumoconiotic lesions. ${ }^{78}$ Changes in acute phase proteins might reflect the same process at the serum level and may be useful as markers of disease activity. On the other hand the acute phase reaction could be used as a marker of individual reactivity against the pathogenic agent. Other study designs would be necessary to check this hypothesis.

In conclusion, an alteration in acute phase proteins was related to pneumoconiosis in some miners. This could be useful as a marker of disease activity, or individual reactivity against the pathogenic agent, or both.

This work was supported by FIS Grant No 88/1182.

Requests for reprints to: G Fernandez-Rego, Instituto Nacional de Silicosis, Dr Bellmunt SN, Oviedo, Spain.

1 Jacobsen M, Rae S, Walton WH, Rogan JM. The relation between pneumoconiosis and dust exposure in British coal miners. In: Walton WH, ed. Inhaled particles III. Vol 2. Old Woking: Unwin Brothers Ltd, 1971:903-17.

2 Gonzalez A, Pedraja V, Eguidazu J, Alonso JM. The relation between pneumoconiosis and dust exposure in Spanish coal miners with comparative studies of different gravimetric samplers. Ann Occup Hyg 1982;26:789-98.

3 Rasche B, Reisner MTR, Islam MS, Thiel H, Zimmermann I, Baumann $\mathrm{H}$, Ulmer WT. Individual factors in the development of coal miners' pneumoconiosis. Ann Occup Hyg 1982; 26:713-22.

4 Rasche B, Baving G, Ulmer WT. Uber die bedeutung des CReactive Proteins (CRP) bei Bergarbeiterpneumokoniose mit Chronish obstruktiver Bronchitis ohne Pneumokoniose. Respiration 1971;28:457-70.

5 Hahon N, Morgan WKC, Petersen M. Serum immunoglobulin levels in coal workers pneumoconiosis. Ann Occup Hyg 1980; 23:165-74.

6 Boyd JE, Collings E, Crofton PM, Blundell G, Davis JMG.

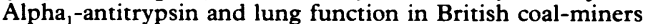
Br J Ind Med 1984;41:455-8.

7 Begin R, Bisson G, Boileau R, Massé S. Assessment of disease activity by gallium- 67 scan and lung lavage in the pneumoconioses. Seminars in Respiratory Medicine 1986;7:271-80

8 Barkman HW, Kanner RE, Rom WN, Welch DM. Gallium-67 citrate imaging in coal workers' pneumoconiosis (CWP). Am Rev Respir Dis 1980;121:221A.

9 Medical Research Council. Definition and classification of chronic bronchitis for clinical and epidemiological purposes. Lancet 1965;i:775-9.

10 International Labour Office. Guidelines for use of the ILO international classification of radiographs of pneumoconiosis. Geneva: ILO, 1980. (Occupational safety and health series No 22.)

11 ATS Statement. Snowbird workshop on standardization of spirometry. Am Rev Respir Dis 1979;119:831-8.

12 Clauss A. Gerinnungsphysiologische Schnellmethode zur Bestimmung des Fibrinogens. Acta Haematol (Basel) 1957; $17: 237-46$.

13 Stuart J. Monitoring the acute phase response. $\mathrm{Br} \mathrm{Med} \mathrm{J}$ 1988;297:1143-4.

14 Dinarello CA. Interleukin-1 and the pathogenesis of the acute phase response. $N$ Engl J Med 1984;311:1413-8.

15 Schmidt JA, Oliver CN, Lepe-Zuñiga JL, Green I, Garry I. Silica stimulated monocytes release fibroblast proliferation factors identical to interleukin-1. A potential role for interleukin-1 in the pathogenesis of silicosis. J Clin Invest 1984;73:1462-72.

Accepted 20 August 1990 